\title{
Uptake and acceptability of medical male circumcision among young males in two culturally distinct settings in South Africa: A longitudinal, community-based study (the MACHO study)
}

\author{
P J Smith, ${ }^{1} \mathrm{PhD} ;$ B Oulo, ${ }^{1} \mathrm{MB} \mathrm{ChB}, \mathrm{MSc} ; \mathrm{M}$ Wallace, ${ }^{2} \mathrm{PhD} ; \mathrm{K}$ Gill, ${ }^{1} \mathrm{MB} \mathrm{ChB}, \mathrm{MPH} ; \mathrm{J}$ A Beijneveld, ${ }^{1} \mathrm{MD}$; \\ T Bennie, ${ }^{1}$ MA; L Myer, ${ }^{3}$ MB ChB, PhD; J J Dietrich, ${ }^{4}$ MA; L F Johnson, ${ }^{5}$ PhD; G Gray, ${ }^{4}$ MB BCh, FC Paed (SA), DSc; \\ L-G Bekker, ${ }^{1} \mathrm{MB}$ ChB, DCH, DTM\&H, FCP (SA), PhD \\ ${ }^{1}$ Desmond Tutu HIV Centre, University of Cape Town, South Africa \\ ${ }^{2}$ Cancer Association of South Africa, Cape Town, South Africa \\ ${ }^{3}$ Division of Epidemiology and Biostatistics, School of Public Health and Family Medicine, Faculty of Health Sciences, University of Cape Town, \\ South Africa \\ ${ }^{4}$ Perinatal HIV Research Unit, Faculty of Health Sciences, University of the Witwatersrand, Johannesburg, South Africa \\ ${ }^{5}$ Centre for Infectious Disease Epidemiology and Research, University of Cape Town, South Africa
}

Corresponding author: P J Smith (philip.smith@hiv-research.org.za)

\begin{abstract}
Background. Young South Africans experience high rates of HIV infection. While nationally scaled medical male circumcision (MMC) can help to curb HIV infection rates in countries such as South Africa (SA), MMC uptake has not been consistent or universal, suggesting variable acceptability among men. Both MMC and traditional male circumcision (TMC) are practised in SA. For male circumcision to be most effective for HIV prevention, it should be performed prior to sexual debut with complete removal of the foreskin.

Objectives. The MACHO (Male Adolescent Choices for HIV Prevention Options) study investigated uptake of and preference for MMC v TMC in two culturally distinct settings in SA.

Methods. This observational, longitudinal, cohort study investigated circumcision preferences and uptake in 100 males (aged 14 - 17 years) and their legal guardians in Cape Town (Western Cape Province) and Soweto (Gauteng Province). Data were collected via surveys administered every 4 months over a 24 -month period.

Results. A total of 100 uncircumcised adolescent boys (Cape Town $n=50$, Soweto $n=50$; mean (interquartile range) age 15 (14 - 16) years) and their guardians were enrolled. At baseline, 42 boys from Soweto ( $84 \%)$ and none from Cape Town expressed a preference for MMC over TMC. Sowetan participants were more likely to elect circumcision (MMC $n=11$ (22\%), TMC $n=1(2 \%)$ ) than those from Cape Town (TMC $n=1(2 \%)$, MMC $n=0$ ) over 13.6 months of follow-up (hazard ratio 18.9; 95\% confidence interval $2.37-150.71 ; p=0.006$ ).

Conclusions. MMC was the preferred option for young men in Soweto compared with those in Cape Town, and this translated into practice. Despite knowledge of the benefits of early MMC, many participants delayed uptake, potentially reducing the MMC benefits before sexual debut. Programmes promoting circumcision should consider the influence of local practices. To realise full HIV prevention benefits, efforts should be made to ensure that circumcision is promoted, and that all circumcision is safe, performed prior to sexual debut, and contextually responsive.
\end{abstract}

S Afr Med J 2020;110(10):1050-1055. https://doi.org/10.7196/SAMJ.2020.v110i10.14110

Estimates suggest that $36 \%$ of all heterosexual transmission of HIV occurs in the 15 - 24-year age group. ${ }^{[1]}$ While HIV counselling and testing is on the increase in young South Africans, ${ }^{[2,3]}$ men use diagnostic and prevention services less than women and are less likely to be in HIV care. ${ }^{[4]}$ Consequently, men have higher levels of HIVrelated mortality than women.

Male medical circumcision (MMC), defined as complete surgical removal of the foreskin, was found to reduce HIV incidence in heterosexual men ${ }^{[5]}$ by $60 \%$ in South Africa (SA) and Kenya, ${ }^{[6,7]}$ and by $67 \%$ in Uganda. ${ }^{[8]}$ The keratinisation of the remaining skin, reduced skin surface area and exposed HIV target cells, and faster drying after sexual contact post circumcision, are some of the factors thought to contribute to prevention. ${ }^{[6,9]}$ This once-off intervention has been shown to accrue cumulative prevention benefit over a sustained period. ${ }^{[8]}$ Moreover, modelling suggests that MMC may offer protection for women and significantly increase the number of infections averted. ${ }^{[10]}$ Accordingly, MMC has been recommended as an efficacious strategy to support combination prevention for men in areas with a high HIV disease burden. ${ }^{[1,12]}$

Both traditional male circumcision (TMC) and MMC are variably practised across SA, with TMC traditionally performed in Limpopo, KwaZulu-Natal, Eastern Cape and Western Cape provinces (Sepedi-, Tshivenda-, isiZulu- and isiXhosa-speaking areas). ${ }^{[13,14]}$ While there is provision for 16- and 17-year-olds to undergo MMC with written parental or guardian permission, the legal age has been set at 18 years. ${ }^{[15]}$ SA data indicate high rates of MMC uptake in boys aged 10 - 14 years outside the Eastern and Western Cape. ${ }^{[16]}$ One SA study found that the mean age for circumcision was 19 years, with $90 \%$ of 472 males circumcised in late adolescence and early adulthood between the ages of 17 and 22 years. ${ }^{[17]}$ Another study conducted in Cape Town, with a large isiXhosa-speaking population who practise TMC, found low acceptability for MMC, that approximately a quarter 
of TMCs were incomplete, and that circumcision took place at $\sim 21$ years. ${ }^{[18]}$ As is widely acknowledged, the study emphasised that TMC was considered a crucial rite of passage into manhood.

After King Shaka Zulu abolished circumcision at the beginning of the 19th century, it was much less frequently practised among Zulu men for $\sim 200$ years. ${ }^{[19]}$ However, in 2009, Zulu King Goodwill Zwelithini decreed circumcision once again advisable owing to the public health benefits. He stated that the current impact of HIV was a reason to change this restriction, suggesting that practice can change in the presence of a supportive policy environment. In contrast, promotional activities for MMC in the Western Cape have trailed behind other provinces, potentially contributing to slower uptake in this province.

\section{Objectives}

The limited data on the acceptability of MMC promotion ${ }^{[18,20]}$ require further investigation to explore desirable features of an ideal HIV prevention service offering an MMC programme for young men. While other studies have investigated acceptability of and attitudes towards circumcision among SA men, ${ }^{[18,20]}$ the present observational study was designed to investigate preferences for and uptake of MMC at youth-friendly clinics in young SA men from different ethnic groups, around the time of sexual debut.

\section{Methods}

This study was part of the CHAMPS (Choices for HIV Adolescent Methods of Prevention in South Africa) project (NIH award 1R01AI094586), which specifically focused on the needs and preferences of adolescents in HIV prevention.

\section{Setting and participants}

The study investigated the acceptability of MMC in young men (aged $14-17$ years) in two locations with culturally distinct practices, Masiphumelele in Cape Town (Western Cape Province) and Soweto (Gauteng Province). Residents of Masiphumelele are largely isiXhosa speaking (Census 2011), and data from the Cape Area Panel Study ${ }^{[17]}$ showed that Xhosa men in Cape Town were generally circumcised at age 17 years or later. ${ }^{[13,15,16]}$ Soweto is a predominantly isiZulu(37\%), Sesotho- (16\%) and Setswana- (13\%) speaking township, with large cohorts of people who speak Xitsonga (9\%), isiXhosa (9\%) and Tshivenda (5\%) (http://www.statssa.gov.za). Participants were recruited through extensive community outreach using links with key stakeholders and were linked to the local MMC service provider. Young males were eligible for the study if they were in good health, tested HIV-negative at screening, were between the ages of 14 and 17 years, and were not circumcised. Overall, 50 participants and their legal guardians were enrolled at each site. In addition to providing assent for study participation, enrolment was contingent upon written consent or agreement by the parent or guardian.

\section{Design}

The MACHO (Male Adolescent Choices for HIV Prevention Options) study was a multi-site, longitudinal mixed-methods cohort study that investigated preferences for, attitudes towards and uptake of elective MMC in 100 males (14 - 17 years), their guardians and other key informants in Cape Town and Soweto. Ethical approval was obtained from the institutional review boards of the universities of Cape Town (ref. no. 05/2013) and the Witwatersrand (ref. no. M130747).

Participants were followed up over a 24-month period and data were collected via researcher-administered surveys. A number of issues related to circumcision were covered, including attitudes towards adolescent male circumcision, adolescent preferences regarding male circumcision, whether perceived protection against HIV infection provided by male circumcision might lead to sexual disinhibition or risk compensation, condom use and practices, and other factors that could affect the decision to undergo circumcision.

\section{Procedure}

After providing informed consent and before being enrolled into the study, potential participants were screened for eligibility, underwent HIV counselling and testing, and were physically examined to determine circumcision status. Participants were requested to complete follow-up visits every 4 months until the end of the study (maximum 20 months). Data were collected from May 2014 until December 2015. Using interviewer-administered questionnaires, participants were required to complete a sexual risk behaviour questionnaire, a circumcision self-report, a circumcision acceptability questionnaire for those who were circumcised, and a social harms and adverse events assessment, as well as to undergo HIV counselling and testing at all visits including enrolment. The questionnaires were piloted with the community advisory boards. Participants also attended men's health information sessions at follow-up visits, which covered a broad range of topics related to physical, emotional and sexual wellness, and the benefits of circumcision. The content of these sessions was developed by the study team in partnership with the community advisory board. These sessions were developed to facilitate retention by building a sense of community among participants, their guardians and the study staff.

At each visit over the duration of the study, (i) acceptability of male circumcision (if performed), (ii) preferences around circumcision, and (iii) sexual risk behaviour were recorded. Legal guardians were also asked to complete a questionnaire on preferences for circumcision (results reported in Table 2) and to attend focus groups on circumcision (not included here). If at any time participants indicated a desire to undergo circumcision, this was recorded. All participants were given referral information to experienced MMC clinics where extensive information about the benefits and risks was provided.

\section{Analysis}

The results were described and bivariate analyses were conducted to identify statistically significant associations $(p<0.05)$ for inclusion in the multivariate analysis. Cox proportional hazards models examined the association between research site (exposure) and time to circumcision (event). Time to circumcision was measured in days, and participants were followed from baseline (day of enrolment) until circumcision, loss to follow-up, or censoring (the last day of followup). The data were analysed in Stata 14 (StataCorp, USA).

\section{Results}

The study enrolled 100 adolescent boys (Cape Town $n=50$, Soweto $n=50)$ (Table 1), with a mean (interquartile range (IQR)) age of 15 (14 - 16) years, and their legal guardians ( $n=97)$. Most participants from the Cape Town site were isiXhosa speaking $(n=44 ; 88 \%)$, while half of the participants at the Soweto site were isiZulu speaking $(n=25 ; 50 \%)$.

At baseline, $27 \%$ had had their sexual debut, with a median (IQR) age of 15 (15 - 17) years. At the final study visit, nearly threequarters $(n=73 ; 73 \%)$ of the participants reported sexual activity. Prior to circumcision, no boys in Cape Town preferred MMC, while in Soweto most (42 of 50) preferred MMC over TMC. Participants had an average of 417 days' follow-up, and in $~ 2$ years of follow-up, 13 boys underwent circumcision, 1 in Cape Town and 12 in Soweto. Each site accounted for 1 of the 2 TMCs, and all 11 MMCs took place 
Table 1. Characteristics of the Cape Town and Soweto cohorts*

\begin{tabular}{|c|c|c|c|c|}
\hline & Cape Town $(N=50)$ & Soweto $(N=50)$ & Total $(N=100)$ & $p$-value \\
\hline Circumcised, $n(\%)$ & & & & 0.001 \\
\hline MMC & 0 & $11(22)$ & $11(11)$ & \\
\hline TMC & $1(2)$ & $1(2)$ & $2(2)$ & \\
\hline Had sex before enrolment, $n(\%)$ & $18(36)$ & $9(18)$ & $27(27)$ & 0.043 \\
\hline Age at enrolment (years), median (IQR) & $15(14-16)$ & $15(15-16)$ & - & 0.082 \\
\hline Had sex during follow-up, $n$ (\%) & $37(74)$ & $36(72)$ & $73(73)$ & 0.824 \\
\hline Age of sexual debut (years), median (IQR) & $15(13.5-16)$ & $15(14-15.8)$ & - & 0.034 \\
\hline In school, $n(\%)$ & $49(98)$ & $50(100)$ & $99(99)$ & - \\
\hline Working, $n(\%)$ & $3(6)$ & 0 & $3(3)$ & 0.086 \\
\hline Race, $n(\%)$ & & & & 0.694 \\
\hline Black & $49(98)$ & $48(96)$ & $97(97)$ & \\
\hline Coloured & $1(2)$ & 0 & $1(1)$ & \\
\hline Other & 0 & $2(4)$ & $2(2)$ & \\
\hline Ethnicity, $n(\%)$ & & & & $<0.001$ \\
\hline Xhosa & $44(88)$ & $12(24)$ & $56(56)$ & \\
\hline Zulu & $1(2)$ & $25(50)$ & $26(26)$ & \\
\hline Sotho/Tswana & $3(6)$ & $9(18)$ & $12(12)$ & \\
\hline Afrikaans & $1(2)$ & 0 & $1(1)$ & \\
\hline Other & $1(2)$ & $4(8)$ & $5(5)$ & \\
\hline \multicolumn{5}{|l|}{ Circumcision by ethnicity, $n$} \\
\hline Xhosa & $1 \mathrm{TMC}$ & $1 \mathrm{TMC}, 1 \mathrm{MMC}$ & & \\
\hline Zulu & 0 & $5 \mathrm{MMC}$ & & \\
\hline Sotho/Tswana & 0 & $3 \mathrm{MMC}$ & & \\
\hline Afrikaans & 0 & 0 & & \\
\hline Other & 0 & $2 \mathrm{MMC}$ & & \\
\hline New HIV infection, $n$ & 0 & 0 & 0 & - \\
\hline Follow-up (days), mean (SD) & $492(169)$ & $341(167)$ & - & - \\
\hline
\end{tabular}

Table 2. Baseline preferences for circumcision

\begin{tabular}{|c|c|c|c|c|c|}
\hline Knowledge and preferences & & $\begin{array}{l}\text { Cape Town }(N=50) \text {, } \\
n(\%)\end{array}$ & $\begin{array}{l}\text { Soweto }(N=50), \\
n(\%)\end{array}$ & $\begin{array}{l}\text { Total }(N=100), \\
n(\%)\end{array}$ & $p$-value \\
\hline \multicolumn{6}{|l|}{ Legal guardian } \\
\hline MMC protects against HIV & Yes & $38(72)$ & $47(94)$ & $85(85)$ & 0.001 \\
\hline Want circumcision & Yes & $50(100)$ & $46(92)$ & $95(95)$ & 0.305 \\
\hline Preference & MMC & $11(22)$ & $42(84)$ & $53(53)$ & $<0.001$ \\
\hline Concerns about TMC & Yes & $32(64)$ & $42(84)$ & $74(74)$ & 0.01 \\
\hline Concerns about MMC & Yes & $28(56)$ & $1(1)$ & $29(29)$ & $<0.001$ \\
\hline \multicolumn{6}{|l|}{ Adolescent } \\
\hline MMC protects against HIV & Yes & $38(76)$ & $48(96)$ & $86(86)$ & 0.019 \\
\hline Want circumcision & Yes & $45(90)$ & $47(94)$ & $92(92)$ & 0.156 \\
\hline Preference & MMC & 0 & $42(84)$ & $42(42)$ & $<0.001$ \\
\hline Concerns about TMC & Yes & $13(26)$ & $43(86)$ & $56(56)$ & $<0.001$ \\
\hline Concerns about MMC & Yes & $22(44)$ & $3(6)$ & $25(25)$ & $<0.001$ \\
\hline
\end{tabular}

in Soweto. Uptake of circumcision differed by ethnicity: $5.4 \%$ in Xhosa (1 TMC in Cape Town, 1 TMC and 1 MMC in Soweto), 19\% in Zulu (5 MMCs in Soweto) and 33\% in Sotho/Tswana (3 MMCs in Soweto) people (for $2 \mathrm{MMCs}$, ethnicity was unspecified). There were no seroconversions during study follow-up.

\section{Knowledge/awareness}

At baseline, almost all legal guardians wanted circumcision for their son or ward, and most adolescents wanted to be circumcised (Table 2).
Eighty-five out of 97 guardians (87\%) were aware that male circumcision protected against HIV and sexually transmitted infections (STIs). The 10 guardians who were unaware of the protection offered by MMC were all from Cape Town $(p=0.001)$. Overall, most adolescents (86\%) were aware of the protection offered by MMC. Participants in Cape Town were less aware of the protection offered by MMC at baseline $(p=0.019)$. At the fourth study visit, the difference between the two sites was not significant $(p=0.164)$. At the fourth study visit, participants' desire to be circumcised had not changed from enrolment. 


\section{Concerns raised}

Compared with Cape Town, TMC was more frequently a concern among participants $(p<0.000)$ and guardians $(p<0.005)$ in Soweto. In contrast, $\mathrm{MMC}$ generated more concerns among participants $(p<0.000)$ and guardians $(p<0.000)$ in Cape Town.

Compared with MMC, TMC was the source of most concern, with 73 guardians $(p=0.005)$ and 62 adolescents $(p<0.000)$ reporting being worried, most in Soweto (Table 3$)$. Adolescents $(n=27)$ and guardians $(n=28)$ in Cape Town were more likely than those in Soweto $(n=3$ and $n=1$, respectively) to state concerns around MMC. Guardians in Cape Town and Soweto were more likely to express concerns about TMC $(n=73)$ than about MMC $(n=29)$. A total of 62 adolescents were worried about traditional circumcision. Around a third of guardians $(n=29)$, mainly in Cape Town, worried about MMC. Approximately a third of adolescents $(n=31)$, mainly in Cape Town, were worried about MMC.

\section{Motives for circumcision}

Overall, 'protection from HIV and STIs' was the most common motive for circumcision (Table 4), with 'religious/cultural' reasons and 'to become a man' coming in second and third. When disaggregated by site, Cape Town participants chose religious/ cultural motivations for circumcision most frequently. Of those who were circumcised, 8 out of 10 participants who gave reasons regarded protection from HIV and STIs as the only reason for circumcision. In the uncircumcised group, cultural motivations were more common.

\section{Sexual risk behaviour}

Pro-circumcision preference was not significantly associated with sexual risk behaviour, age of sexual debut, sexually active status over the course of the study, or age at enrolment.

\section{Association between circumcision and research site}

There were more circumcisions (TMC and MMC) in Soweto $(n=12)$ than in Cape Town $(n=1)$. Participants in Soweto were more likely to elect circumcision (TMC $n=1$, MMC $n=11$ ) than those in Cape Town (TMC $n=1$ ) over time (hazard ratio 18.9; 95\% confidence interval 2.37 - 150.71; $p=0.006$ ) (Table 5, Fig. 1).

\section{Discussion}

Uptake of circumcision in this study overall was low in the cohort, in which the Soweto component contributed most to circumcision numbers. It was evident from participant responses that those in Cape Town preferred TMC and were more likely to offer concerns regarding MMC than those in Soweto. In contrast, participants in Soweto were significantly more likely to exhibit preference for MMC and offer concerns regarding TMC than those in Cape Town. Despite reasonable knowledge about the benefits of early MMC, bolstered by the men's sexual health educational sessions, the evidence from this study echoes the results of other research showing that many young males delay uptake, ${ }^{[16]}$ and Xhosa participants preferred TMC over MMC. While research on male circumcision in SA is rich, this study was novel because it followed young men in high HIV disease burden communities in SA at the time of sexual debut. Additionally,

Table 3. Concerns about circumcision

\begin{tabular}{|c|c|c|c|c|c|c|c|c|}
\hline & \multicolumn{4}{|c|}{ Adolescents, $n$} & \multicolumn{4}{|c|}{ Guardians, $n$} \\
\hline & Cape Town & Soweto & Total & $p$-value & Cape Town & Soweto & Total & $p$-value \\
\hline TMC concerns & 19 & 43 & 62 & 0.000 & 31 & 42 & 73 & 0.005 \\
\hline Safety of the procedure & 5 & 25 & 30 & & 9 & 28 & 37 & \\
\hline Pain & 8 & 9 & 17 & & 7 & 2 & 9 & \\
\hline Cost & 5 & & 5 & & 8 & & 8 & \\
\hline Lack of expertise/training to circumcise & & & 0 & & 4 & 4 & 8 & \\
\hline Tradition & & 4 & 4 & & & 3 & 3 & \\
\hline Partial/inappropriate circumcision & 1 & 2 & 3 & & 2 & & 2 & \\
\hline Length of process & & 1 & 1 & & & 1 & 1 & \\
\hline Cold weather & & & 0 & & & 1 & 1 & \\
\hline Not knowing what happens & & & 0 & & & 1 & 1 & \\
\hline Missing school & & & 0 & & & 1 & 1 & \\
\hline Complications with the procedure & & & 0 & & 1 & & 1 & \\
\hline Fear & & 1 & 1 & & & & 0 & \\
\hline Not practised in the community/family & & 1 & 1 & & & & 0 & \\
\hline Not specified & & & & & & 1 & 1 & \\
\hline MMC concerns & 27 & 3 & 31 & 0.000 & 28 & 1 & 29 & 0.000 \\
\hline Will not be regarded as a man & 12 & & 12 & & 5 & & 5 & \\
\hline Not practised in my culture & 4 & 1 & 5 & & 9 & & 9 & \\
\hline Not practised in the community/family & 5 & & 5 & & 9 & & 9 & \\
\hline Cost & 3 & & 3 & & 2 & & 2 & \\
\hline Safety of the procedure & 1 & & 1 & & 2 & 1 & 3 & \\
\hline Pain & 2 & & 2 & & 1 & & 1 & \\
\hline Fear & & 1 & 1 & & & & 0 & \\
\hline No teaching about manhood & 1 & & 1 & & & & 0 & \\
\hline Not specified & & 1 & 1 & & & & 0 & \\
\hline
\end{tabular}


Table 4. Adolescents' motives for circumcision

\begin{tabular}{|c|c|c|c|c|c|}
\hline & \multicolumn{2}{|c|}{ Cape Town } & \multicolumn{2}{|c|}{ Soweto } & \multirow[b]{2}{*}{$\begin{array}{l}\text { Total }(N=100) \text {, } \\
n(\%)\end{array}$} \\
\hline & $\begin{array}{l}\text { Uncircumcised } \\
(N=49), n(\%)\end{array}$ & $\begin{array}{l}\text { Circumcised } \\
(N=1), n(\%)\end{array}$ & $\begin{array}{l}\text { Uncircumcised }^{*} \\
(N=38), n(\%)\end{array}$ & $\begin{array}{l}\text { Circumcised }^{*} \\
(N=12), n(\%)\end{array}$ & \\
\hline Religious/cultural & $43(88)$ & $1(100)$ & 0 & $1(8)$ & $45(45)$ \\
\hline To please family/community & $29(59)$ & $1(100)$ & 0 & 0 & $30(30)$ \\
\hline To become a man & $41(84)$ & $1(100)$ & $2(5)$ & 0 & $44(44)$ \\
\hline Hygiene & $40(82)$ & $1(100)$ & $2(5)$ & 0 & $43(43)$ \\
\hline Protection from HIV/STIs & $41(84)$ & $1(100)$ & $27(71)$ & $9(75)$ & $78(78)$ \\
\hline To improve sexual pleasure & $25(51)$ & 0 & 0 & 0 & $25(25)$ \\
\hline More attractive to women & $17(35)$ & 0 & 0 & 0 & $17(17)$ \\
\hline It looks better & $18(37)$ & 0 & 0 & 0 & $18(18)$ \\
\hline
\end{tabular}

\begin{tabular}{|c|c|c|c|c|c|c|}
\hline & Unadjusted HR & $95 \% \mathrm{CI}$ & $p$-value & Adjusted HR & $95 \% \mathrm{CI}$ & $p$-value \\
\hline Age (years) & 1.36 & $0.80-2.31$ & 0.254 & 1.16 & $0.64-2.12$ & 0.630 \\
\hline \multicolumn{7}{|l|}{ Sites } \\
\hline Cape Town & 1 (base) & & & & & \\
\hline Soweto & 19.85 & $2.51-156.82$ & 0.005 & 18.90 & $2.37-150.71$ & 0.006 \\
\hline
\end{tabular}

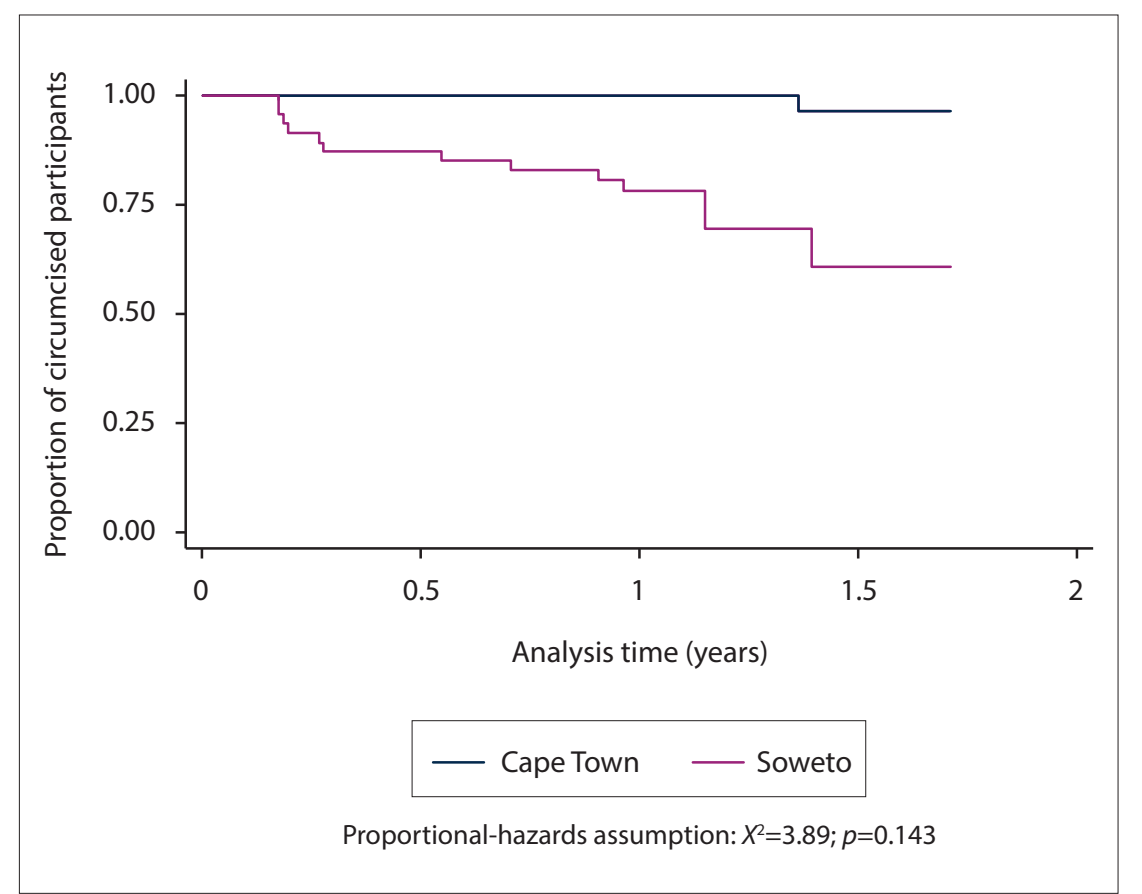

Fig. 1. Kaplan-Meier survival time (days) until circumcision (traditional male circumcision and male medical circumcision), with log-rank test for equality of survivor functions.

the findings are useful because the study suggests that sexual health research and interventions should be designed for the intended context and population.

Soweto had higher overall circumcision uptake and MMC uptake. Xhosa participants accounted for a minority of circumcisions
21 years, ${ }^{[15,16]}$ these participants may have had lower uptake of circumcision owing to the preference of Xhosa men to undertake TMC when slightly older.

Although participants' and legal guardians' knowledge about the protection offered by MMC was high, and almost all participants reported wanting circumcision, uptake was generally slow and limited in this cohort, suggesting some barriers or concerns. Concerns among the respondents from the two cities were different. In Soweto, concerns were raised by participants and guardians regarding safety of TMC. Conversely, concerns about MMC were mainly raised among participants in Cape Town. Their most cited concerns were not being accepted in the community, going against their cultural beliefs, or failing to be regarded as a man, if they opted for MMC. Qualitative data may provide more detailed insights about the contextual and cultural influences upon circumcision uptake, and how to adapt the service to the context.

\section{Study limitations}

There were a number of limitations to this study. While the age group was specifically chosen to investigate circumcision around sexual debut, when HIV acquisition risk increases, very few participants underwent circumcision in this time frame, and it would have been instructive to extend 
the follow-up period. The cohort was small, which may have led to overestimated or missed associations, so associations with circumcision status should be viewed with caution. Accordingly, since most (92\%) participants were pro-circumcision, the study was not powered to detect differences in behaviour between the pro- and anti-circumcision groups. Finally, since TMC is culturally practised in Cape Town, there is far more acceptance there for this method of circumcision. This underlying ethos may also influence decisions for a number of reasons. Since most staff were Xhosa, their cultural beliefs and practice may also have a significant role in influencing circumcision election.

\section{Conclusions}

Male circumcision is an integral part of the culture in many places in SA. MMC is an important male-specific tool in the HIV prevention package for Africa, where much of the epidemic is fuelled by heterosexual sex. Programmes to promote circumcision should take into consideration cultural and traditional mores including ensuring collaboration with cultural Xhosa leaders and people. Efforts should be made to ensure that all circumcision is safe, culturally sensitive, effective and acceptable. Additionally, public messaging based on policy should be tested with target populations, and their input should be used to ensure the message is heard as intended.

Declaration. The research for this study was done in partial fulfilment of the requirements for PJS's PhD degree at the University of Cape Town. Acknowledgements. We thank the young participants and their families for their willingness to volunteer and participate in the research. We also thank all the clinical teams and the terrific study co-ordinators, who made the experience safe and friendly for the participants.

Author contributions. Conception, design, and oversight: L-GB, GG, MW, LFJ, LM, PS, TB. Collection of data and assembly: KG, JAB, TB, JD. Data analysis and interpretation: $\mathrm{PS}, \mathrm{BO}, \mathrm{KG}, \mathrm{JAB}, \mathrm{TB}$. Manuscript writing and editing: all authors. Final approval of manuscript: all authors.

Funding. This study was supported by NIH grant 1R01AI094586, 'Choices for Adolescent Prevention Methods in Southern Africa' (CHAMPS).

Conflicts of interest. None.
1. Johnson L, Dorrington R, Bradshaw D, Pillay-Van Wyk V, Rehle T. Sexual behaviour patterns in South Africa and their association with the spread of HIV: Insights from a mathematical model. Demogr Res 2009;21(11):289-340. https://doi.org/10.4054/DemRes.2009.21.1

2. Maughan-Brown B, Lloyd N, Bor J, Venkataramani A. Increasing access to HIV testing: Impacts on . Maughan-Brown B, Lloyd N, Bor J, Venkataramani A. Increasing access to HIV testing: Impacts on
equity of coverage and uptake from a national campaign in South Africa. April 2015. http://hdl.handle. equity of coverage and uptake from a nation

3. Maughan-Brown B, Lloyd N, Bor J, Venkataramani AS. Changes in self-reported HIV testing during South Africa’s 2010/2011 national testing campaign: gains and shortfalls. J Int AIDS Soc 2016;19(1):20658. https://doi.org/10.7448/IAS.19.1.20658

4. Dovel K, Yeatman S, Watkins S, Poulin M. Men's heightened risk of AIDS-related death: The legacy of gendered HIV testing and treatment strategies. AIDS 2015;29(10):1123-1125. https://doi.org/10.1097/ QAD. 0000000000000655

5. Siegfried N, Muller M, Deeks JJ, Volmink J. Male circumcision for prevention of heterosexual acquisition of HIV in men. Cochrane Database Syst Rev 2003, Issue 3. Art. No.: CD003362. https://doi. org/10.1002/14651858.CD003362

6. Auvert B, Taljaard D, Lagarde E, Sobngwi-Tambekou J, Sitta R, Puren A. Randomized, controlled intervention trial of male circumcision for reduction of HIV infection risk: The ANRS 1265 Trial. PLoS Med 2005;2(11):e298. https://doi.org/10.1371/journal.pmed.0020298

7. Bailey RC, Moses S, Parker CB, et al. Male circumcision for HIV prevention in young men in Kisumu, Kenya: A randomised controlled trial. Lancet 2007;369(9562):643-656. https://doi.org/10.1016/S01406enya: A random

8. Gray RH, Kigozi G, Kong X, et al. The effectiveness of male circumcision for HIV prevention and effects on risk behaviors in a post-trial follow up study in Rakai, Uganda. AIDS 2012;26(5):609-615. https://doi. org/10.1097/QAD.0b013e3283504a3f

9. Patterson BK, Landay A, Siegel JN, et al. Susceptibility to human immunodeficiency virus-1 infection of human foreskin and cervical tissue grown in explant culture. Am J Pathol 2002;161(3):867-873. https:// doi.org/10.1016/S0002-9440(10)64247-2

10. Hallett TB, Alsallaq RA, Baeten JM, et al. Will circumcision provide even more protection from HIV to women and men? New estimates of the population impact of circumcision interventions. Sex Transm Infect 2011;87(2):88-93. https://doi.org/10.1136/sti.2010.043372

11. Westercamp N, Bailey RC. Acceptability of male circumcision for prevention of HIV/AIDS in subSaharan Africa: A review. AIDS Behav 2007;11(3):341-355. https://doi.org/10.1007/s10461-006-9169-4

12. World Health Organization. Voluntary medical male circumcision for HIV prevention: Progress brief. July 2018. http://www.who.int/hiv/pub/malecircumcision/vmmc-progress-brief-2018/en/ (accessed
J July 2018. http:/// 11 December 2018).

13. Connolly C, Simbayi LC, Shanmugam R, Nqeketo A. Male circumcision and its relationship to HIV infection in South Africa: Results of a national survey in 2002. S Afr Med J 2008;98(10):789-794

14. Kripke K, Chen P-A, Vazzano A, et al. Cost and impact of voluntary medical male circumcision in South Africa: Focusing the program on specific age groups and provinces. PLoS ONE 2016;11(7):e0157071. https://doi.org/10.1371/journal.pone.0157071

15. Vincent L. 'Boys will be boys': Traditional Xhosa male circumcision, HIV and sexual socialisation in contemporary South Africa. Cult Health Sex 2008;10(5):431-446. https://doi. org/10.1080/13691050701861447

16. Johnson LF, Dorrington RE. Modelling the impact of HIV in South Africa's provinces: 2019 update. Centre for Infectious Disease Epidemiology and Research working paper. June 2019. https://www. thembisa.org/downloads (accessed 10 September 2020).

17. Maughan-Brown B, Venkataramani AS, Nattrass N, Seekings J, Whiteside AW. A cut above the rest: Traditional male circumcision and HIV risk among Xhosa men in Cape Town, South Africa. J Acquir Immune Defic Syndr 2011:58(5):499-505. https://doi.org/10.1097/QAI.0b013e31823584c1

18. Mark D, Middelkoop K, Black S, et al. Low acceptability of medical male circumcision as an HIV/AIDS Mark D, Middelkoop K, Black S, et al. Low acceptability of medical male circumcision as an HIV/AIDS
prevention intervention within a South African community that practises traditional circumcision. S Afr prevention intervention within a South African community that

19. Timbs L. An In(ter)vention of tradition: Medical male circumcision in KwaZulu-Natal, 2009 - 2016. Timbs L. An In(ter)vention of tradition: Medical male circumcision in KwaZulu-N
J Natal Zulu Hist 2018;32(1):55-77. https://doi.org/10.1080/02590123.2018.1447534

20. Lagarde E, Dirk T, Puren A, Reathe R-T, Bertran A. Acceptability of male circumcision as a tool for preventing HIV infection in a highly infected community in South Africa. AIDS 2003;17(1):89-95. https://doi.org/10.1097/00002030-200301030-00012

Accepted 27 May 2020. 